\title{
Effectiveness of School based Awareness Programmes against Tobacco among Users and Non- Users- A Cross- Sectional Study from Rural Kerala, India
}

\author{
Radhakrishnan Jayakrishnan ${ }^{1 *}$, Jagathnath Krishna Kumara Pillai Mohanan \\ Nair $^{2}$, Geetha Seema ${ }^{3}$, Gigi Thomas ${ }^{1}$, Paul Sebastian ${ }^{4}$
}

\begin{abstract}
Background: Known is the fact that adult tobacco users mostly had their initiation into the habit during the adolescence period. The current study was conducted to evaluate the impact of awareness programmes among adolescent students in rural Kerala, India, in terms of knowledge enhancement on tobacco hazards. Methods: A total of 10 high schools and higher secondary schools from one educational sub district were selected using multi stage sampling design. Male students in the age group 13-19 years studying in class IX and X (high school category) and class XI and XII (higher secondary school) were included in the study. The effectiveness was assessed using pre and post training evaluation forms based on mean knowledge scores. Results: 1,114 students participated by filling both the forms (mean age 15.6, SD 1.3). The response rate was $92.8 \%$. The prevalence of 'current users' in the study was $4.3 \%$ (95\% CI 3.11- 5.49). Overall difference in mean knowledge scores among study subjects was evident when pre and post training responses were compared $(\mathrm{p}<0.001)$. The difference in knowledge scores was evident among 'never users' of tobacco before and after the awareness programmes $(p<0.0001)$. However, no significant difference in mean scores was observed among 'ever users' of tobacco $(p=0.584)$, age groups of ever users $(p=0.208)$, students of high schools $(p=0.242)$ and higher secondary schools $(p=0.994)$. Comparison of never, ever and current users revealed significant difference between 'never' and 'current' users $(\mathrm{p}=0.001)$. However, no such difference was observed between 'ever' and 'current' users ( $p=0.138)$ and 'ever' versus 'never' users $(p=0.099)$. Conclusion: The study was useful to improve knowledge among school students in general. However, newer strategies have to be tested to understand the best possible measures for tobacco awareness training among adolescent tobacco users.
\end{abstract}

Keywords: Tobacco - schools- awareness- rural- Kerala

Asian Pac J Cancer Prev, 20 (7), 2027-2032

\section{Introduction}

Tobacco continues to pose a major threat to humanity globally, claiming more than 6 million lives every year (Britton, 2017). The consequence of tobacco exposure is not limited to cancer alone but affects almost every organ of the body. Strengthening tobacco control measures has resulted in a decline in tobacco use in developed countries. However, a shift is now evident in low and middle income countries, where tobacco consumption has increased convincingly among younger age groups (Stone and Peters, 2017). Adolescent tobacco consumption, if left unchecked, is a major risk factor for non-communicable diseases in adulthood (Singh et al., 2017; Park 2011).

In India, the Global Adult tobacco Survey-2016-17 (GATS-2), conducted among subjects 15 years and older, reported of nearly a third of the population (28.6\%) using tobacco in some form or the other. However, the prevalence of tobacco users among minors in the 15-17 years' age group was reported at $4 \%$. The result has dual implications in the Indian context. On one side, the results look promising considering a decrease of tobacco prevalence by $6 \%$ units from the year 2009-10 and among minors from $10 \%$ to $4 \%$. (Mohan et al., 2018; MoHFW Government of India, 2016-17). But on the other side, the outcome points to the enormous measures needed to further control this problem in a country which has over a billion population, having the world largest youth population and also being the second largest consumer of tobacco (Mishra et al., 2012).

Though there are various tobacco control measures to check the demand and supply of tobacco, sensitization programmes targeting young population who are at risk of tobacco exposure were found useful to generate awareness

${ }^{1}$ Division of Community Oncology, ${ }^{2}$ Division of Cancer Epidemiology and Biostatistics, ${ }^{4}$ Former Director, Regional Cancer Centre, ${ }^{3}$ Department of Periodontics, Sri Sankara Dental College, Vennicode, Thiruvananthapuram, Kerala, India. *For Correspondence: jaykrishnan999@gmail.com 
(Morrell et al., 2008). In this context, health education programmes have to be given in a sustainable manner to the vulnerable groups particularly adolescent school children and young adults. However, these programmes have to be extensively scrutinized as to make sure whether the concerned programme would have any impact on the current tobacco users.

With this background, a study was conducted in the southern state of Kerala, India, to determine the impact of health promotion programmes to improve awareness against tobacco among adolescent students.

Kerala's health care and social reforms have been widely acclaimed and the health indicators of the state are even close to those of developed countries (Sauvaget et al., 2011). Tobacco control is an area where Kerala has made remarkable strides in recent years. According to the GATS-2 report, from $21.4 \%$ prevalence in the year 2009-10, tobacco consumption has decreased to $12.7 \%$ in 2016-17. However, there are problems for Kerala which needs to be rectified. The current smoking prevalence in Kerala among males aged 15 years and above is $19.6 \%$ compared to the national prevalence of $19 \%$. There was not much of a difference observed in the tobacco prevalence among minors aged 15- 17 years when the GATS results were compared. While it was $3.1 \%$ in the year 2009-10, a marginal increase (3.7\%) rather than reduction was observed in the Kerala GATS- 2 report. The smokeless tobacco prevalence in this group has increased from $3.1 \%$ to $3.7 \%$ (Tata Institute of Social Sciences, 2016-17). The popular versions are gutkha/panmasala containing tobacco that also has ingredients such as crushed arecanut, catechu, paraffin wax, slaked lime and flavouring agents. This report again shows that adolescents are the most vulnerable section of the population. Though the Cigarettes and other tobacco Products Act 2003 of India gives emphasis on prohibition of tobacco sales to minors and near educational institutions, accessibility of tobacco products need to be restricted further in all manners to control this problem.

The school environment has always been a focus of attention to concentrate efforts to prevent and control tobacco use. The advantages are manifold, including the accessibility and reach of awareness among school students at a single setting, and a focus on health education that could fit with the daily curriculum activities of schools (Thomas et al., 2013).

The present paper illustrates the impact of awareness programmes among ever users of tobacco in high school and higher secondary school students of rural Thiruvananthapuram district in Kerala state and to elucidate whether there is a significant shift in knowledge on tobacco awareness after delivering the message among ever users and never users. Before commencement of the study, the Scientific Committee of the Institutional Review Board of Regional Cancer Centre, Thiruvananthapuram had approved the study protocol.

\section{Materials and Methods}

The study was conducted in the rural schools of Thiruvananthapuram district in Kerala state. In Kerala, for ease of administration, each revenue district is categorized as an educational district and additionally into educational sub districts. Out of the 3 educational districts, which also included 12 educational sub districts, one educational district was chosen randomly. In the government school category, around 40 high school/higher secondary schools are present in each educational district. For study purpose, only government schools/government aided schools were selected. High schools and higher secondary schools in a particular place are located in the same campus though they are functioning independently. In all these schools, education is free for all students irrespective of the socioeconomic status. Hence student enrollment is high particularly in the rural areas. Due to the high prevalence of tobacco use in the rural areas of India (Gupta et al., 2010) and the possibility that adolescence being a transition phase in a person's life, where the vulnerability of getting exposed to risk factors such as tobacco was also taken into consideration to initiate the study.

Using a multistage sampling method, 10 schools (5 high schools and 5 higher secondary schools) out of 17 schools were selected from one educational sub district using computer generated random numbers. 10 awareness programmes were conducted representing 10 schools. Sampling unit was the class division. Students enrolled in class IX, X, XI and XII were eligible for participating in the study. 35 to 50 students were present in each class division. One division was selected randomly from each class. Males students were enrolled for the study due to the reason that tobacco habits were mainly reported among them while among female students, the prevalence was negligible (Muttappallymyalil et al., 2012; Jayakrishnan et al., 2011). Information was collected from each student before and after delivering anti- tobacco awareness sessions. Details of sampling unit, inclusion and exclusion criteria, study questionnaire and methods of awareness on tobacco hazards have already been reported (Jayakrishnan et al., 2016).

Pre and post training evaluation forms were used to assess the impact of awareness among each study subject. Pre-tested semi-structured questionnaires were used for the study. Both pre and post training questionnaires were distributed before the programme with a unique number provided in the questionnaire set and were advised not to reveal their identity in the forms. The pre-training questionnaire comprised of two sections. The first section included general questions related to the demographic characteristics, tobacco use history of the individual's and their parent's. While the second part consisted of two open ended questions and 14 multiple choice questions. The post-training questionnaire was the same as the pre-training part except for the first section which was totally excluded. The maximum score a subject could achieve was 16 which coincide with 1 mark for each question. The questions were framed to understand the knowledge of the student on common ingredients in tobacco, diseases caused due to tobacco use and knowledge on tobacco legislation. The research team explained each question to the subjects and also ensured that the information received from each student would be kept confidential. Students were told to fill the pre-training form initially and advised to fill the post 
training form after the awareness programme. Participation to the study was purely voluntary. The resource person (RJ) conducted awareness programme using audiovisual slides. Before concluding the programme, a documentary film on tobacco developed by the Regional Cancer Centre, Thiruvananthapuram, was also screened.

In the present study, "ever user" of tobacco was defined as a person who had experienced tobacco at least once during the academic year, while weekly three days or more of tobacco use was termed as "current user". Statistical analysis was done using the SPSS version 11 software. Chi square statistics was used for categorical variables and if the expected value of a cell was less than five, Fisher's exact test statistics was used. For continuous variables, Students t- test was used to test mean differences between two groups, while, Analysis of Variance Test (ANOVA) was used to test mean differences between more than two groups. For those significant variables, Bonferroni multiple comparison test was used to find the significantly differing groups.

\section{Results}

\section{Subject Characteristics}

Self reporting questionnaires were distributed to 1,200 high school and higher secondary school students of which 1,114 students participated. The response rate was $92.8 \%$. Pre-training and post-training information was collected from 539 HS students and 575 HSS students. Self-reported ever users of tobacco in the current academic year was $7.4 \%$ (95\% CI 5.86-8.94) of which $4.3 \%$ subjects were current users (95\% CI 3.11- 5.49). Among ever users ( $\mathrm{n}=83$ ), 49\% were current users of tobacco (Table 1). (Jayakrishnan et al., 2016). HSS students constituted $66.2 \%$ of the tobacco users in the study. $43.2 \%$ of HSS students reported of cigarette use while $35.7 \%$ of the HS students were panmasala users (Table 2).

Knowledge difference among study participants before and after awareness programme
Table 1. Study Sample Characteristics

\begin{tabular}{lcccc}
\hline Factors & $\begin{array}{c}\text { Never users } \\
(\mathrm{n}=1031)\end{array}$ & $\begin{array}{c}\text { Ever users } \\
(\mathrm{n}=83)\end{array}$ & Total & p-value \\
\hline Age group & & & & \\
$\quad \leq 14$ years & $254(97.7)$ & $6(2.3)$ & 260 & $0.0001^{*}$ \\
15-17 years & $738(91.8)$ & $66(8.2)$ & 804 & \\
$\geq 18$ years & $39(78.0)$ & $11(22)$ & 50 &
\end{tabular}

Tobacco use among students based on class division

$\begin{array}{lcccc}\text { Class IX } & 191(95.5) & 9(4.5) & 200 & \\ \text { Class X } & 320(97.3) & 19(5.8) & 339 & 0.019^{*} \\ \text { Class XI } & 218(91.2) & 21(8.8) & 239 & \\ \text { Class XII } & 302(89.9) & 34(10.1) & 336 & \end{array}$

*Statistically significant at $5 \%$. Figures in parenthesis are row percentages; Source: Jayakrishnan R, Seema G, Krishna KMJ et al (2016). Tobacco and Alcohol Use and the Impact of School Based Antitobacco Education for Knowledge Enhancement among Adolescent Students of Rural Kerala, India. J Addict, 2016:9570517

Overall difference in knowledge among study subjects was evident after the awareness programme when pre and post training responses were compared $(\mathrm{p}<0.001)$.

Comparison of high school and higher secondary school students

Significant difference was observed in the mean knowledge scores among high school students before and after the awareness programme $(\mathrm{p}=<0.001)$. While there was improvement in knowledge among high school students, no such difference was observed among higher secondary school students $(\mathrm{p}=0.959)$.

\section{Comparison of never and ever users of tobacco}

The difference in knowledge in terms of knowledge enhancement was evident among never users of tobacco before and after the awareness programmes $(p<0.0001)$, while, no such difference was observed among ever users of tobacco $(\mathrm{p}$ value $=0.584)$.

Further, age-group wise assessment of knowledge scores of ever users also observed no significant

Figure 1. Legend?

Table 2. Tobacco Use Pattern among Study Subjects based on Education and Age Group

\begin{tabular}{|c|c|c|c|c|c|}
\hline & \multicolumn{5}{|c|}{ Total participants $(\mathrm{N}=1114)$, Type of tobacco use $(\mathrm{n}=83)$} \\
\hline & Panamasala & Cigarette & Bidi & Betelquid & Total \\
\hline \multicolumn{6}{|c|}{ Student's category $(\mathrm{HS}=539, \mathrm{HSS}=575)$} \\
\hline High school (HS) & $10(35.7)$ & $7(25)$ & $6(21.4)$ & $5(17.9)$ & $28(100)$ \\
\hline Higher secondary school (HSS) & $14(25.5)$ & $24(43.6)$ & $9(16.4)$ & $8(14.5)$ & $55(100)$ \\
\hline Total & $24(28.9)$ & $31(37.3)$ & $15(18)$ & $13(15.6)$ & $83(100)$ \\
\hline$P$ value ${ }^{a}$ & & & & & 0.424 \\
\hline \multicolumn{6}{|l|}{ Age group of tobacco users } \\
\hline$<=14$ & $3(50)$ & 0 & $3(50)$ & 0 & $6(100)$ \\
\hline $15-17$ & $19(28.8)$ & $24(36.4)$ & $11(16.7)$ & $12(18.2)$ & $66(100)$ \\
\hline$>=18$ & $2(18.2)$ & 7 (66.6) & $1(9.1)$ & $1(9.1)$ & $11(100)$ \\
\hline Total & $24(28.9)$ & $31(37.3)$ & $15(18)$ & $13(15.6)$ & $83(100)$ \\
\hline P value ${ }^{b}$ & & & & & 0.092 \\
\hline
\end{tabular}


Table 3. Comparison of Mean Knowledge Scores among Tobacco Users

\begin{tabular}{lcccc}
\hline Category $(\mathrm{n}=83)$ & \multicolumn{2}{c}{ Mean Knowledge scores } \\
& Pre-training (SD) & P value & Post-training (SD) & P value \\
\hline Ever user $(\mathrm{n}=49)$ & $8.88(3.18)$ & 0.6 & $9.41(3.61)$ & $0.03^{*}$ \\
Current user $(\mathrm{n}=34)$ & $8.50(3.26)$ & & $7.12(5.31)$ & 0.99 \\
Ever user HS $(\mathrm{n}=28)$ & $8.14(3.45)$ & 0.24 & $8.46(3.84)$ & \\
Ever user HSS $(\mathrm{n}=55)$ & $9.02(3.06)$ & & $8.47(4.84)$ & \\
*Significant at 5\% level using students T test & & & &
\end{tabular}

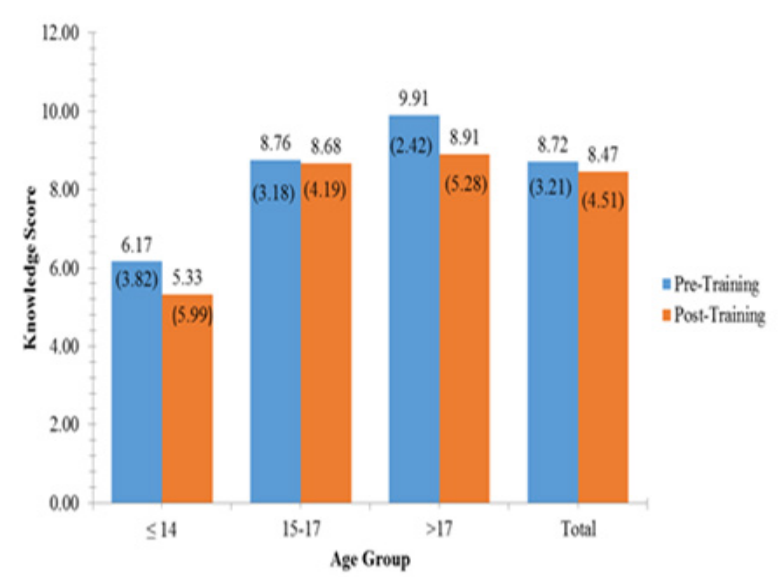

Figure 1. Comparison of Pre-Training and Post-Training mean Knowledge Scores (SD) among ever Users of Tobacco

difference in the scores before the session $(p=0.06)$ and after the awareness session $(\mathrm{p}=0.208)$ which indicates no significant improvement in mean knowledge scores among different age groups before and after the awareness programme (Figure 1).

\section{Knowledge difference (ever vs. current users)}

Analysis of ever vs. current users revealed no significant difference in knowledge scores before the awareness programme $(\mathrm{p}=0.600)$. On the other hand, significant difference was observed among the two groups in the post training evaluation $(p=0.030)$ which points to the fact that 'ever users' had improved their mean knowledge scores after the awareness programme compared to 'current users' (Table 3).

Comparison of never, ever and current users of tobacco

Comparison of never, ever and current users revealed significant difference between 'never' and 'current' users $(\mathrm{p}=0.001)$ while no such difference was observed between 'ever' and 'current' users $(p=0.138)$ and 'ever' versus 'never' users $(\mathrm{p}=0.099)$. Among ever users of tobacco, no significant difference was observed among high school and higher secondary school groups $(p=0.424)$ and among different age groups $(p=0.092)$.

\section{Discussion}

This cross-sectional study highlights the benefits and limitations of tobacco awareness programmes targeting adolescent students in rural schools conducted in the year 2014-15 in rural Kerala. The study explored the possibility of improving awareness among school students utilizing resource persons to conduct awareness programmes and also using videos of tobacco hazards in schools to find out the extent of knowledge acquired by study subjects. In this study, the self reported 'ever-users' (7.4\%) and 'current users' (4.3\%) was reasonably high compared to the GATS-2 report of Kerala where tobacco prevalence among youth (15-17 years) was reported at 3.7\%. Unlike urban areas, increased prevalence of tobacco use among the general public and adolescent group in rural areas was reported by studies from India (Chockalingam et al., 2013; Sabnis et al., 2016). The present study was conducted in rural settings where the socio-demographic characteristics of the rural community in general viz. education, occupation and income could have been reasonably low. Moreover, the laxity in strict enforcement of tobacco legislation in rural areas complemented with lack of awareness on tobacco hazards and tobacco control laws particularly selling restrictions near schools might have augmented the sale of tobacco products to a certain extent. Hence it is of paramount importance to educate adolescent students on the need for implementing effective tobacco control strategies to check illicit trade of tobacco and further to make them aware of the consequences of tobacco use likely to occur in adulthood. The current study demonstrated the effectiveness of one-time awareness programme done in schools to improve awareness of students as a whole, which is a positive sign. However, there were certain loose strings to be tightened in terms of awareness among tobacco users. This was reflected in the 'no significant difference' in knowledge scores among tobacco users before and after awareness programmes. In the current study, age-group wise comparison also noted no significant difference in knowledge scores before and after intervention.

The impact of awareness programmes against tobacco was looked upon by studies from different perspectives. To understand the intention of taking up the habit in future, programmes targeting school children had found it successful when specific focus on smoking and oral health was taught in schools (Nazar and Almas, 2017). Similar result was observed in a study conducted in South India, where interventions benefitted adolescent students to develop a decision against future tobacco use and highlighted the need for enhancing awareness among students to develop an unfavorable attitude to future tobacco use (Ballal et al., 2016). Impact of awareness using various methods to augment knowledge among tobacco users was also reported. In a study conducted in the state of New Delhi, India, attempts to recall 
spot messages on tobacco hazards screened at cinema theatres was found unsuccessful among tobacco users (Kaur et al., 2012). Further, a longitudinal study had reported of effective antismoking television campaigns to reduce smoking initiation among younger adolescents compared to older adolescents (Siegal and Biener, 2000). Comparison on tobacco use, beliefs and risk awareness among university students of 23 countries reported of considerable variation in awareness, particularly low levels of awareness on health risk of smoking in developing countries (Stepoe et al., 2002). The Cochrane review 2013 findings recommended the effectiveness of school based interventions in reducing long term smoking rates, in the line of intervention including social skills development and social competence rather than information alone strategies (Thomas et al., 2013).

The current study looked into the extent of how far the awareness was effective before and after information dissemination, in terms of improving the knowledge against tobacco. In our study, no improvement in scores was observed when age-group wise analysis was done among 'ever-users'. The possibility of less attentive attitude of students or a state of denial cannot be ignored among this group, as there were reports of mental distress being a factor for less academic performance among students with substance use (Mekonen et al., 2017; Dessie et al., 2013). Moreover, financial hardships, familial influence and psycho-social influence could also lead to poor academic performance (Abdu-Raheem, 2013). These factors could have its reflection in the current study as well resulting in less attention to awareness sessions. Currently the school health programme of the National Health Mission, Government of India gives importance for physical and mental health of the school children. Emotional and behavioral problems among students are referred to higher centres for further management. However identifying students with tobacco habits is crucial and is often a challenge to the authorities to unravel the source of sale of tobacco and the students involved in buying those products. The current study also has its own limitations. Our sample size of ever users of tobacco was small which could have affected the study results. Adolescent female students were excluded from the study which needs to be studied separately. However, the current study raises the question of how general awareness programmes could improve the knowledge among tobacco users considering the fact that there was a significant effect among never users.

In a diverse country like India, where nearly one third of adults are tobacco users, it seems imminent to initiate awareness programmes among adolescent groups. Multi-modal interventions are to be tested in different community settings to understand specific campaigns that suit adolescent users to improve their knowledge on tobacco hazards.

\section{Study approval}

The study was approved by the scientific committee of the Institutional Review Board, Regional Cancer Centre, Thiruvananthapuram.
Financial support

Nil.

\section{Conflicts of interest}

There are no conflicts of interest.

\section{Acknowledgements}

We would like to acknowledge Professor Ramani S Wesley, Regional Cancer Centre, Thiruvananthapuram for her technical guidance in conducting the study. We are grateful to the school authorities and the participants for their support in organizing and conducting the study.

\section{References}

Abdu-Raheem BO (2013). Sociological factors to drug abuse and the effects on secondary school students academic performance in Ekiti And Ondo States, Nigeria. Contemp Issues Educ Res, 6, 233-40

Ballal K, Kulkarni M, Agrawal A, Kamath A, Kumar M (2016). Knowledge and attitude regarding tobacco and its use among adolescent students. Ntl J Community Med, 7, 519-3.

Britton J (2017). Death, disease and tobacco. Lancet, 389, 1861-2.

Chockalingam K, Vedhachalam C, Rangasamy S, et al (2013). Prevalence of tobacco use in urban, semi urban and rural areas in and around Chennai city. India PLoS One, 8, e76005.

Dessie Y, Ebrahim J, Awoke T (2013). Mental distress among university students in Ethiopia: A cross sectional survey. Pan Afr Med J, 15, 95.

Gupta V, Yadav K, Anand K (2010). Patterns of tobacco use across rural, urban, and urban-slum populations in a North Indian community. Indian J Commun Med, 35, 245-1.

Jayakrishnan R, Geetha S, Binukumar B, Sreekumar, Lekshmi K (2011). Self-reported tobacco use, knowledge on tobacco legislation and tobacco hazards among adolescents in rural Kerala State. Indian J Dent Res, 22, 195-9

Jayakrishnan R, Seema G, Krishna KMJ, et al (2016). Tobacco and Alcohol use and the impact of school based anti tobacco education for knowledge enhancement among adolescent students of rural Kerala, India. J Addict, 2016, ID 9570517.

Kaur J, Kishore J, Kumar M (2012). Effect of anti- tobacco audiovisual messages on knowledge and attitude towards tobacco use in North India. Indian J Community Med, 37, 227-1.

Mekonen T, Fekadu W, Mekonnen TC, Workie SB (2017). Substance use as a strong predictor of poor academic achievement among university students. Psychiatry $J, 2017$, ID 7517450 .

Ministry of Health and Family Welfare, Government of India. Global Adult tobacco Survey/ India Fact sheet 201617. Available at https://mohfw.gov.in/sites/default/files/ GATS-2\%20FactSheet.pdf. Accessed on 16-06-2018.

Mishra GA, Pimple SA, Shastri SS (2012). An overview of the tobacco problem in India. Indian J Med Paediatr Oncol, 33, 139-5.

Mohan P, Lando HA, Panneer S (2018). Assessment of tobacco consumption and control in India. Indian J Clin Med, 9, 1-8.

Morrell HER, Cohen LM, Dempsey JP (2008). Smoking prevalence and awareness among undergraduate and health care students. Am J Addict, 17, 181-6.

Muttappallymyalil J, Divakaran B, Thomas T, et al (2012). Prevalence of tobacco use among adolescents in north Kerala, India. Asian Pac J Cancer Prev, 13, 5371-4.

Nazir MA, Almas K (2017). Awareness about the effects of Asian Pacific Journal of Cancer Prevention, Vol 202031 
tobacco consumption on oral health and the possibility of smoking behavior among male Saudi schoolchildren. Eur J Dent, 11, 29-5.

Park SH (2011). Smoking and adolescent health. Korean $J$ Pediatr, 54, 401-4.

Sabnis R, Sahu K, Thakur D, et al ( 2016). Urban and rural disparity in tobacco use and knowledge about oral cancer among adolescents: An epidemiological survey on 12 and 15 -year school going students. J Int Soc Prev Community Dent, 6, 226-1.

Sauvaget C, Ramadas K, Fayette JM, et al (2011). Socio-economic factors and longevity in a cohort of Kerala State, India. Indian J Med Res, 133, 479-6.

Siegal M, Biener L (2000). The Impact of an antismoking media campaign on pogression to established smoking: Results of a longitudinal youth study. Am J Public Health, 90, 380-6.

Singh A, Bassi S, Nazar GP, et al (2017). Impact of school policies on non-communicable disease risk factors - a systematic review. BMC Public Health, 17, 292.

Steptoe A, Wardle J, Cui W, et al (2002). An international comparison of tobacco smoking, beliefs and risk awareness in university students from 23 countries. Addiction, 97, 1561-1.

Stone E, Peters M (2017). Young low and middle-income country (LMIC) smokers-implications for global tobacco control. Transl Lung Cancer Res, 6, 44-6.

Tata Institute of Social Sciences, Ministry of Health and Family Welfare- Government of India, World Health Organisation. Global Adult tobacco Survey 2, India 2016-17, Kerala fact sheet. Available at http://www.tiss.edu/uploads/files/30 KL.pdf. [Accessed on 21-06-2018].

Thomas RE, McLellan J, Perera R (2013). School-based programmes for preventing smoking. Cochrane Database Syst Rev, 4. Art. No.: CD001293. DOI: 10.1002/14651858. CD001293.pub3.

This work is licensed under a Creative Commons AttributionNon Commercial 4.0 International License. 